\section{ORIGINAL RESEARCH}

F. Gomez

W. Escobar

A.M. Gomez

J.F. Gomez

C.A. Anaya

\title{
Treatment of Carotid Cavernous Fistulas Using Covered Stents: Midterm Results in Seven Patients
}

BACKGROUND AND PURPOSE: Carotid cavernous fistulas (CCF) can be effectively treated by using different therapeutic alternatives such as detachable balloons and detachable coils, alone or in combination with N-butyl-2-cyanoacrylate ( $n$-BCA) or Onyx. Stents have also been used in an attempt to improve preservation of the parent artery while still occluding the fistula. We present our experience using balloon-expandable covered stents to treat CCF, focusing on arterial wall reconstruction. To our knowledge, this is the first series with midterm follow-up between 3 months and 3.5 years.

MATERIALS AND METHODS: From the 46 CCF treated at our institution between November 1998 and September 2006, a total of 7 posttraumatic direct CCF were treated using polytetrafluoroethylene (PTFE)-covered stents between April 2003 and September 2006. Five were treated with covered stents alone. One patient with transection of the internal carotid artery (ICA) first underwent bare stent placement to provide support for the covered stent. One patient had to be treated with coils and $n$-BCA.

RESULTS: Control angiograms obtained in the 7 patients demonstrated occlusion of the fistula and preservation of the ICA in all cases. There was no mortality and no immediate postprocedural morbidity. There was 1 case of morbidity identified at 1-month follow-up with asymptomatic occlusion of the ICA; the other 6 patients had angiographic follow-up between 3 and 42 months (mean, 18.4 months), with persistent occlusion of the fistulas, patent stent grafts, and no significant intimal hyperplasia.

CONCLUSIONS: PTFE-covered stents are evolving as a promising intracranial therapeutic alternative to treat CCF and preserve the parent artery by reconstructing the arterial wall. They should be considered in patients in whom fistulas cannot be successfully occluded with detachable balloons or detachable coils. More investigation is required to further develop their specifications and indications.

$\mathbf{F}$

ollowing the introduction of detachable latex balloons by Serbinenko ${ }^{1}$ in 1974 , Debrun et $\mathrm{al}^{2-5}$ popularized the detachable balloon technique to treat carotid cavernous fistulas (CCF). As the first endovascular tool to treat CCF, detachable balloons became the method of choice with reported success rates ranging between $75 \%-88 \%$ in occluding the fistulas and preserving the patency of the parent internal carotid artery (ICA). ${ }^{3,5-11}$ However, despite representing an excellent alternative to surgery, balloons could not always be used if preservation of the parent artery was desired. This drawback led to the continuous search for alternative ways to treat CCF while attempting to preserve the artery. ${ }^{8,10,12}$ Several treatment options followed, including detachable coils and cyanoacrylates. Detachable coils in particular have proved to be an excellent therapeutic option to occlude CCF in different circumstances when balloons could not be used because of either the technical limitations or lack of availability. Nevertheless, some limitations observed with the use of coils to occlude CCF still can be identified when herniation of a coil loop or the coil tip into the parent vessel occurs and cannot be repositioned. This

Received October 20, 2006; accepted after revision March 23, 2007.

From the Department of Radiology (F.G., W.E.), Centro Medico Imbanaco, Cali, Colombia; the Department of Radiology (A.M.G.), University of California, Los Angeles, Calif; the Department of Radiology (J.F.G.), Tulane University, New Orleans, La; and the Department of Radiology (C.A.A.), VA Hospital Greater Los Angeles, Calif.

Paper previously presented in part at: Annual Meeting of the American Society of Neuroradiology, May 3, 2006; San Diego, Calif.

Please address correspondence to Fernando Gomez, MD, DIME, Av. 5 Norte No. 20N-75, Cali, Colombia; e-mail: fergomez98@hotmail.com

DOI 10.3174/ajnr.A0636 poses a risk for embolization, which has been reported occasionally to require parent artery occlusion. ${ }^{7,12}$

Additional complex techniques have been described using a transarterial and/or transvenous approach to occlude the fistula by using the detachable coils alone or in combination with N-butyl-2-cyanoacrylate ( $n$-BCA) with or without balloon assistance. ${ }^{7,12-17}$ Onyx (ev3, Irvine, Calif) has also been used in combination with detachable coils in a few patients with satisfactory clinical and angiographic results up to 3 months. ${ }^{18,19}$ More recently, bare stent-assisted coil placement has proved to be another alternative particularly useful when arterial reconstruction is required, with no evidence of fistula recurrence and preservation of the parent artery at 3- to 6-month follow-up. ${ }^{14}$ To our knowledge, only a few cases of covered stents to treat CCF with short-term follow-up have been described in the English literature. ${ }^{20-22}$ We present our experience in 7 cases of CCF treated with covered stents with midterm follow-up between 1 month and 3.5 years (mean, 18.4 months).

\section{Patients and Methods}

From the 46 cases of CCF treated at our institution between November 1998 and September 2006, a total of 7 posttraumatic direct CCF were treated by using covered stents between April 2003 and September 2006. The description of the patient population and technique is summarized in the Table. There were 6 men and 1 woman, ranging between 21 and 54 years of age (mean, 32.7 years). All the fistulas were posttraumatic, 6 of them located in segment $C 4$, and 1, in segment C6 of the Bouthillier classification. ${ }^{23}$ All the procedures were performed 
with the patient under general anesthesia. All except 1 patient was premedicated with clopidogrel, $75 \mathrm{mg} /$ day, and acetylsalicylic acid (ASA), $100 \mathrm{mg} /$ day, starting 3 days before the procedure. Patient 4 was premedicated with a loading dose of $600-\mathrm{mg}$ clopidogrel and 100-mg ASA; with this regimen, clopidogrel platelet inhibition began at 2 hours and ASA, at 1.5 hours. During the procedure, anticoagulation was provided with intravenous heparin; an initial bolus of $5000 \mathrm{U}$ was administered and then titrated to maintain the activated clotting time around 250 seconds.

The decision to treat CCF by using covered stents was based on a combination of factors that included the presence of a favorable carotid siphon anatomy and the inability to deliver a detachable balloon (please refer to "Discussion") or its nonavailability. We considered favorable siphons to be those with a straighter less tortuous course. Other treatment options such as detachable coil embolization was also entertained; however, on the basis of the favorable anatomy and prior successful experience of the authors (F.G., W.E.) with the use of covered stents in the treatment of traumatic vascular lesions of the cervical carotid and vertebral arteries, it was decided to treat these CCF with covered stents. To advance a covered stent to the level of the CCF, we used a triaxial access system. We started with an ultralong sheath (Shuttle; Cook, Bloomington, Ind), which was advanced to the level of the common carotid artery. A 6F Envoy catheter (Cordis, Miami Lakes, Fla) was then advanced coaxially over the wire into the ICA. Using a microcatheter system (Tracker Excel-14; Boston Scientific, Natick, Mass) and a Transcend-14 wire (Boston Scientific), we catheterized the middle cerebral artery and advanced the catheter tip approximately to the level of the angular artery. The guidewire was then replaced with a ChoICE Extra Support Exchange Guidewire (Boston Scientific-Target, Fremont, Calif). The covered stent, Jostent GraftMaster (Abbott Vascular Devices, Amersfoort, the Netherlands), was then advanced over the wire. The Jostent is a covered stent characterized by a polytetrafluoroethylene (PTFE) membrane layered between 2 stainless steel stents with reduced wall thickness. The navigation of the stent delivery system through the vascular loops can be challenging due to the rigidity of the system. However, as described by Saatci et al, ${ }^{24}$ when extra support is required, this stiffness can be used to the operator's advantage when the long sheath and guide catheter can be further advanced into the carotid artery by sliding them over the shaft of stent delivery system by using it as the guide. With this technique, it is possible to bring the covered stent to the level of the cavernous carotid artery where the fistulas are located, provided there is a favorable anatomy with a relatively open siphon. During the interval reported, we had 1 additional case of a direct CCF in which the covered stent could not be satisfactorily advanced to the level of the fistula due to a markedly tortuous carotid siphon. This patient was successfully treated with detachable coils.

The stent is positioned under roadmap in the working projection, and the final positioning is confirmed with a predeployment angiogram to occlude the fistula and prevent occluding the anterior choroidal artery or the posterior communicating artery. In our series, only 1 ophthalmic artery origin had to be covered with the stent, without clinical consequence. In this case, the ophthalmic artery continued to be filled by collateral flow through the external carotid artery. ${ }^{25}$ Deployment control angiograms were obtained in several projections. Following stent placement, 3 of the 7 patients developed significant spasm that was successfully treated with direct slow intraarterial injection of 0.5 - $\mathrm{mg}$ nimodipine $(0.1 \mathrm{~mL}$ of $50 \mathrm{mg} / 10 \mathrm{~mL}$ solution diluted into $2.4 \mathrm{~mL}$ of saline) through the guide catheter. After the procedure, all patients were admitted to the intensive care unit for 

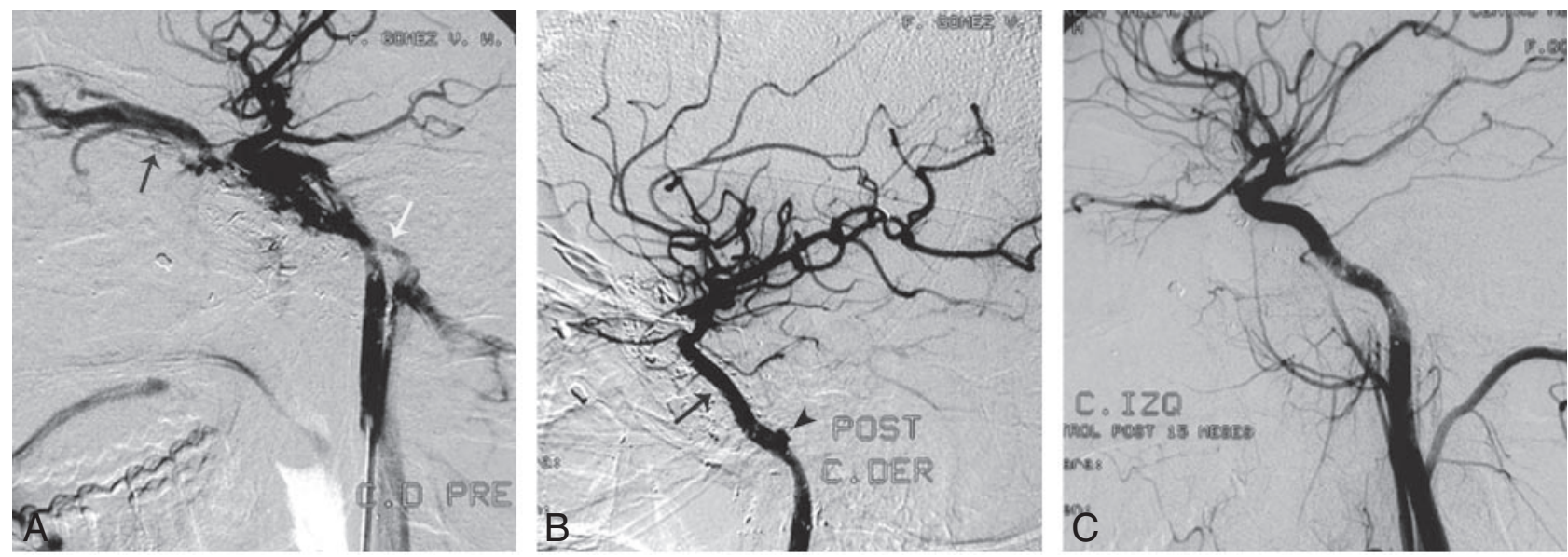

Fig 1. A, Patient 2. Selective left ICA angiogram demonstrates a CCF after a gunshot wound, with filling of the superior ophthalmic vein (black arrow) and inferior petrosal sinus (white arrow). $B$, Immediate control post-covered stent deployment (black arrow) shows complete occlusion of the fistula. A small pseudoaneurysm is noticed in the petrous carotid artery (black arrowhead), which was managed conservatively. C. Follow-up after 15 months shows a normal artery without recanalization of the fistula. There has been spontaneous resolution of the small pseudoaneurysm, and there is no intimal hyperplasia.

observation. They were then discharged with 100-mg/day ASA for life and 75-mg/day clopidogrel for 3 months. All patients had clinical and angiographic follow-up.

\section{Results}

The 7 patients with CCF were treated with covered stents. The ICA was preserved in all cases (100\%). There was no mortality and no immediate postprocedure morbidity. From the technical perspective, the stent grafts were successfully deployed in all patients. Four patients required only 1 stent graft. One patient had residual filling of the fistula and was successfully treated by immediately placing a second covered stent. In 1 patient, we first placed a bare stent to reconstruct the artery and provide support to the covered stent placed to seal the fistula by using the bare stent graft technique. ${ }^{25}$ In 1 patient, the covered stent had to be complemented with detachable coils (Detach platinum J-coil; William Cook Europe, Bjaeverskov, Denmark) and Lipiodol:Histoacryl solution (Lipiodol; Guerbet, Genova, Italy; Histoacryl; B/Braun, Melsungen, Germany) due to persistent endoleak despite repeat balloon inflation. In 2 of our patients (patients 6 and 7), we chose stent graft placement as the first therapeutic option based on favorable anatomy consistent with less tortuous carotid artery, no critical side branches adjacent to the site of the fistula, and the accumulated positive experience in the prior cases. Before the procedure, 5 of the 7 patients had ophthalmic symptoms that completely resolved after therapy. One patient had anticipated, persistent blindness; however, the cosmetic defect improved. The patient with cortical venous drainage and temporoparietal lobe hemorrhage recovered without rebleed or residual neurologic deficit.

\section{Procedural Complications}

Three of the 7 patients developed transitory spasm of the cavernous carotid artery during the positioning of the covered stent, which was noticed in the immediate control angiograms. These patients were successfully treated with direct intra-arterial injection of $2.5-\mathrm{mL}(0.5 \mathrm{mg})$ nimodipine; prompt resolution of the spasm was demonstrated in the following angiogram after a single nimodipine dose.

\section{Immediate Posttreatment Complications}

All patients with CCF treated with covered stents were admitted to the intensive care unit for observation. They all had an uneventful immediate postprocedure hospital course without complications.

\section{Follow-Up Results and Complications}

There was 1 patient with angiographic morbidity who developed asymptomatic occlusion of the ICA (patient 1). His immediate control angiogram demonstrated excellent flow with no obvious ICA dissection; this patient interrupted the prescribed antiplatelet medications soon after discharge, which we believe precipitated thrombotic occlusion of the stent graft. The 1-month follow-up angiogram demonstrated the occlusion of the stented ICA and preservation of the intracranial circulation through collateral flow. The other 6 patients had angiographic follow-up between 3 months and 42 months (mean, 21.3 months), all showing persistent exclusion of the fistula with patent stent graft and intracranial ICA. Only 1 patient (patient 3) demonstrated minimal intrastent neointimal hyperplasia, which was asymptomatic and remained unchanged throughout his 37-month follow-up. The other 5 patients had no evidence of intimal hyperplasia. We discuss the more illustrative cases below.

\section{Case 1}

Patient 2 was a 21 -year-old man who presented with a left CCF secondary to a gunshot wound 2 years before. Findings of a physical examination demonstrated marked proptosis and erythema but preserved ocular movements. Metallic and osseous fragments were identified in the CT scan in the left temporal fossa and parasellar region. The angiogram showed a left CCF draining into a markedly enlarged ophthalmic vein and into the inferior petrosal sinus (Fig $1 A$ ). Conventional therapy with endovascular silicone balloon occlusion was initially attempted with a GoldValve GVB No. 16 (Minvasys, Gennevilliers, France), but 2 balloons ruptured on inflation, pierced by spiculated osseous fragments. It was decided to treat the fistula with a covered stent. Using the triaxial system, we advanced a covered Jostent GraftMaster $(4 \times 12 \mathrm{~mm})$ to the level of the 

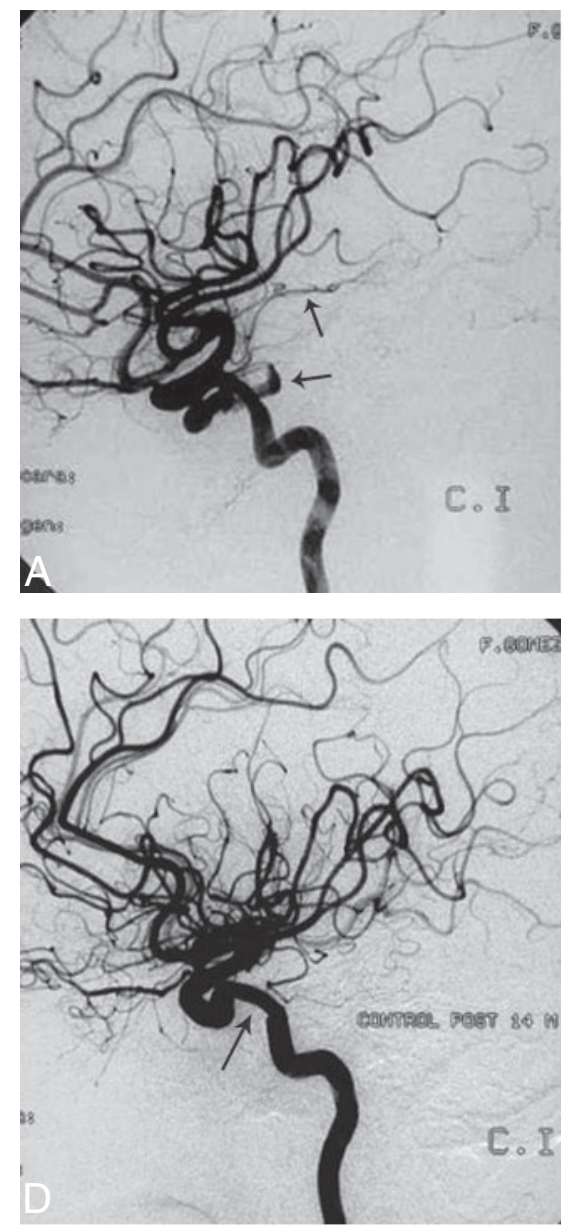
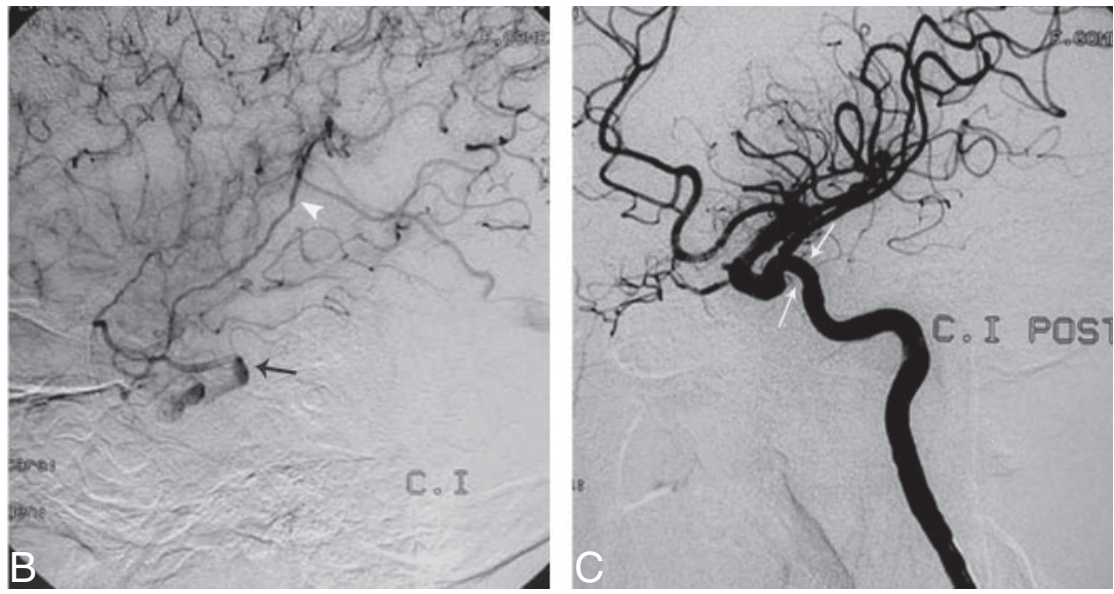

Fig 2. $A$ and $B$, Patient 4. Angiogram with arterial $(A)$ and venous $(B)$ phase images showing a CCF with retrograde cortical venous drainage (black arrows and white arrowhead). Notice the separation of the cortical veins due to the intracerebral hematoma identified in a previous MR image (not shown). In this case, a covered stent was used because the fistula was too small to accept a balloon. C, Control poststent graft deployment (white arrows). There is complete occlusion of the fistula. $D$, Fifteen-month control angiogram demonstrates persistent occlusion of the fistula with minimal intrastent intimal hyperplasia (black arrow), which remained stable in the 42-month angiographic follow-up (not shown). cavernous carotid artery (Bouthillier segment 4) where it was deployed. ${ }^{23}$ Control angiography demonstrated partial obliteration of the fistula, with residual filling of the inferior petrosal sinus (not shown). A second Jostent GraftMaster $(4 \times 16$ $\mathrm{mm}$ ) was placed overlapping the proximal end of the first one, completely occluding the fistula (Fig $1 B$ ). A small petrous pseudoaneurysm (segment C2) was identified and managed conservatively. The patient was discharged on antiplatelet therapy with ASA (100 mg/day) and clopidogrel (75 mg/day). Follow-up angiograms at 9, 14, and 23.5 months demonstrated persistent occlusion of the CCF with preserved ICA, spontaneous resolution of the small petrous pseudoaneurysm, and no evidence of intimal hyperplasia (Fig $1 C$ ).

\section{Case 2}

Patient 4 was a 39-year-old man who had blunt head trauma with skull base fracture during a motor vehicle crash (MVC). Two months later, he developed sudden right hemiplegia. MR imaging demonstrated a large left temporoparietal intra-axial hematoma (not shown). The initial angiogram demonstrated a CCF with a small fistula orifice and a small cavernous sinus. There was retrograde cortical venous drainage into the left Sylvian vein, which precipitated the hemorrhage (Fig $2 A,-B$ ). The presence of a CCF with retrograde cortical drainage and associated intracerebral hematoma constitutes a therapeutic emergency. Because the size of the orifice and the cavernous sinus did not allow the use of a detachable balloon and the carotid siphon configuration was suitable for stent placement, we decided to treat it with this technique. Using the triaxial system, we advanced a $4 \times 12 \mathrm{~mm}$ covered stent (Jostent GraftMaster) and deployed it in the cavernous carotid (segment 4), completely occluding the fistula (Fig $2 C$ ). Follow-up angiography at 2, 14.9, and 42 months demonstrated a normal ICA artery without intrastent intimal hyperplasia and with no recurrence of the fistula (Fig $2 D)$.

\section{Case 3}

Patient 5 was a 21-year-old man who was involved in a highspeed MVC, with severe multiple trauma that included maxillofacial and skull base fractures associated with right-sided ophthalmoplegia, blindness, and overt findings of CCF on physical examination. The right ICA angiogram demonstrated no enhancement of the intracranial circulation, with complete flow deviation into the fistula and extensive venous drainage (Fig 3A). The fistula drained into the ophthalmic vein, facial vein, ipsilateral cavernous and inferior petrosal sinuses, and via the coronary sinus into the contralateral cavernous and petrosal sinuses. To better characterize the fistula, we repeated right-sided carotid and vertebral angiography with ipsilateral carotid compression (flow-reduction maneuvers of Mehringer-Hieshima and Heuber respectively), ${ }^{26}$ demonstrating a transection of the cavernous ICA (segment 4). The right intracranial ICA territory was maintained by collateral circulation. We established a 2-step strategy; first, we placed a bare stent to guarantee adequate wall apposition and provide added support. Once the procedure was completed, we placed a covered 

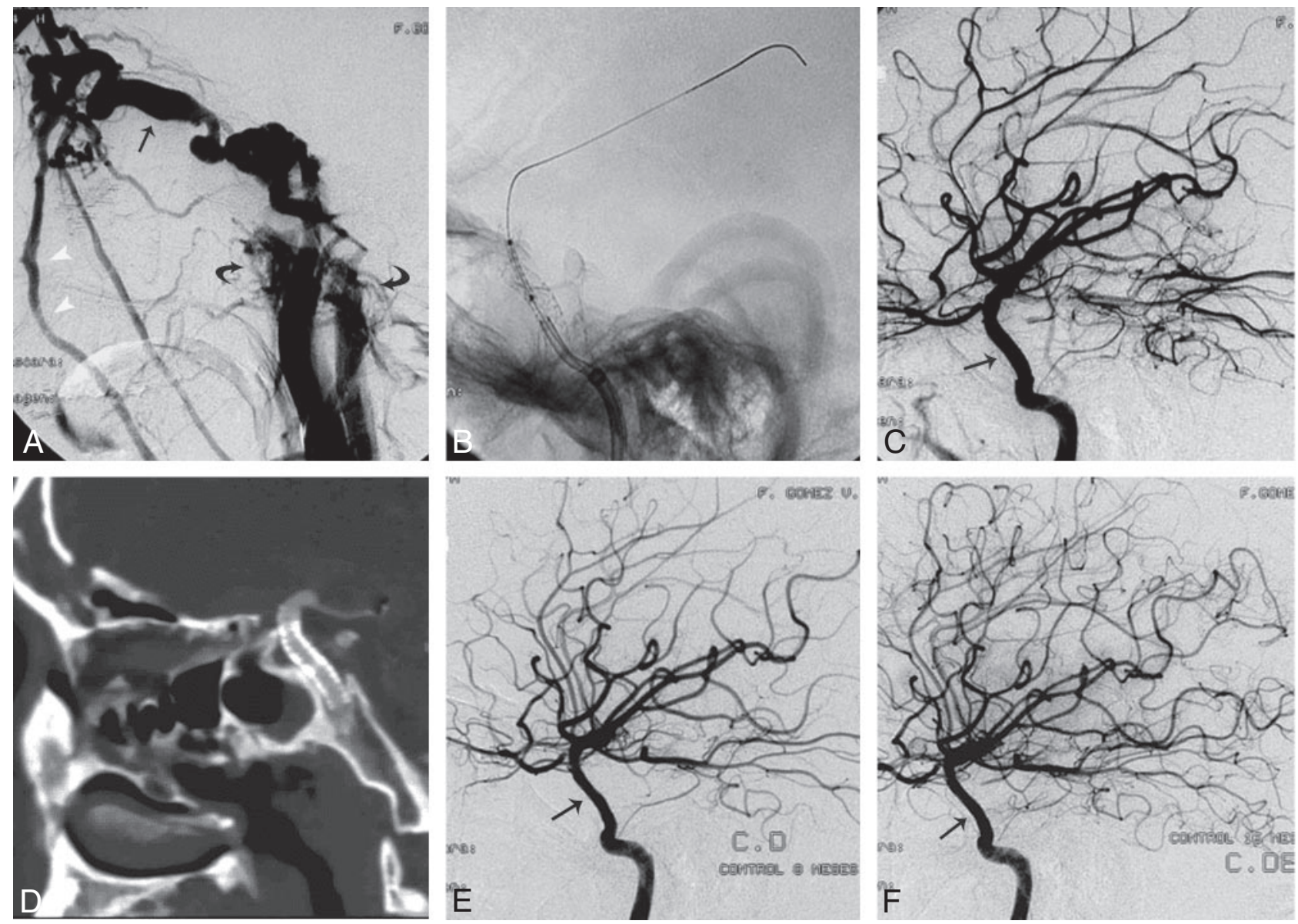

Fig 3. A, Patient 5. Selective right ICA angiogram demonstrates a high-flow CCF with arterial phase enhancement of a markedly enlarged superior ophthalmic vein (black arrow), facial veins (white arrowheads), and both inferior petrosal sinuses (curved arrows). This is a case of near-complete cavernous ICA transection with nonvisualization of the right anterior and middle cerebral arteries due to complete deviation of the flow into the fistula. $B$, There is an exchange wire stabilized in one of the distal middle cerebral artery branches. A bare stent has just been deployed in the cavernous carotid artery to reconstruct the vessel wall and provide stability to the covered stent, which is being positioned inside the bare stent at the exact location of the fistula. $C$, Control postdeployment shows occlusion of the fistula with re-establishment of the intracranial flow through the right ICA. There is straightening (arrow) of the cavernous ICA with no hemodynamic consequence in the control angiogram. $D$, Three-month follow-up with CT angiography. Here the sagittal reformat shows the straightening of the cavernous carotid artery with the stent in place and preserved patency. $E$ and $F$. Angiographic follow-up at 8 and 15 months demonstrates a normal intracranial ICA without recurrence of the fistula or significant intrastent intimal hyperplasia (black arrows).

stent to finalize the arterial reconstruction and seal the fistula. ${ }^{25}$ The triaxial access system was set, and a bare coronary stent, Liberté Monorail, $5 \times 24 \mathrm{~mm}$ (Boston Scientific), was successfully deployed to begin the 2-step arterial wall repair (Fig 3B). We immediately completed the reconstruction and occluded the CCF by placing the covered stent (Jostent GraftMaster, $4 \times 12 \mathrm{~mm}$ ) inside the bare stent. Once the stent was deployed, the angiogram showed complete resolution of the fistula with re-establishment of the intracranial circulation through the ipsilateral right ICA (Fig 3C). Follow-up at 3 months with multidetector row $\mathrm{CT}$ showed a patent intracranial ICA, with the characteristic rectification of the stented segment and occlusion of the fistula (Fig 3D). Angiographic follow-up at 8 and 14.9 months showed a widely patent intracranial ICA without neointimal hyperplasia and no recurrence of the fistula (Fig $3 E,-F)$.

\section{Case 4}

Patient 3 was a 21-year-old man who had a blunt head trauma when hit by a car while riding his bicycle. He later developed chemosis and proptosis. The angiogram demonstrated a rare type of direct CCF located above the level of the ophthalmic artery and the anterior clinoid process (Bouthillier segment C6). ${ }^{27}$

Using the same technique previously described, we advanced a covered stent $(3.5 \times 14 \mathrm{~mm}$ Jostent GraftMaster $)$ above the level of the anterior clinoid process, where the fistula was identified. Special attention was paid not to occlude the anterior choroidal artery or the posterior communicating artery. Following the liberation of the stent, an endoleak was identified in the control angiogram and balloon re-inflation was performed to improve wall apposition. However, the endoleak worsened. This patient could not be treated by placing a second covered stent because of the proximity to the origin of the anterior choroidal artery. Using a microcatheter system, we catheterized the fistula and completed treatment of the CCF with detachable coils (Detach platinum J-coil, William Cook Europe) and Histoacryl (3:1 Lipiodol:Histoacryl solution). Control angiograms up to 37 months showed stable findings with occluded fistula and no intimal hyperplasia.

\section{Discussion}

Following their introduction in the 1970s, detachable balloons quickly became the method of choice to treat CCF, with re- 
ported success rates of $75 \%-88 \%$ in preserving the patency of the parent ICA. ${ }^{3,5,7-11}$ Although they are excellent therapeutic devices, there are some situations in which detachable balloons cannot be used if preservation of the parent artery is desired. These include the following: 1) a small orifice that does not allow the passage of the balloon; 2) the cavernous sinus being too small and causing the balloon to herniate into the parent ICA; 3) sharp osseous fragments within the sinus that can cause the balloon to rupture on inflation; 4) a markedly enlarged cavernous sinus that cannot be completely filled even with the use of multiple balloons, leaving empty spaces that prevent complete occlusion and cure; and 5) transection of the cavernous ICA. One additional circumstance that limits the use of detachable balloons is their limited availability.

All these situations have led to the search for alternative ways to treat the fistula while attempting to preserve the artery, even if this is not always possible. ${ }^{8,10,12}$ Different techniques have been described using a transarterial and/or transvenous approach to occlude the fistula with detachable coils, $n$-BCA, and Onyx with or without balloon assistance. ${ }^{7,12,15-18}$ Detachable coils have proved to be an excellent therapeutic option to treat CCF in those various circumstances in which balloons have failed or cannot be used, and they have the added advantage of being more widely available. Bare stents and covered stents have been recently introduced as another set of alternatives to provide support to the coils or to directly obliterate the fistula. ${ }^{14,20-22,28}$ The CCF with complete transection of the ICA constitutes a particularly challenging therapeutic situation that, in most cases, requires occlusion of the ICA to cure the fistula. ${ }^{8,10,12,14,17}$ Preservation of the artery in patients with CCF and severe laceration of the ICA has been feasible by using simultaneous bare stent and balloon-assisted coil obliteration. $^{14}$

We describe our experience using covered stents as the alternative method to treat CCF, focusing on the reconstruction of the injured arterial wall as the main way to achieve occlusion of the fistula. ${ }^{29}$ The use of covered stents to treat CCF has been described in previous case reports, with successful occlusion of the fistula and preservation of the ICA in 5 patients with follow-up between 3 and 14 months (mean, 8.2 months). ${ }^{20-22}$ Additional encouraging experience with the intracranial use of covered stents has been reported for the treatment of intracranial aneurysms and pseudoaneurysms..$^{21,24,25,30-35}$ In our series, we successfully occluded 7 of 7 fistulas. Six of the 7 fistulas were completely occluded by using covered stents; 5 of them, by using covered stents alone. One patient underwent planned bare stent placement previous to the release of the covered stent, to provide additional support and allow precise positioning. One patient had to be treated with coils due to residual endoleak originating too close to the anterior choroidal artery.

The mean angiographic follow-up in our 7 patients was 18.4 months, demonstrating a patency rate of $85.7 \%$. This patency rate was affected by the patient who was noncompliant to the prescribed antiplatelet regimen and developed early ICA occlusion noticed during the 1-month follow-up. In our series, 1 patient showed minimal intimal hyperplasia with no hemodynamic significance. The other 6 patients showed no intimal hyperplasia. All the findings of angiograms remained stable with time; the condition of our 1 patient with minimal intimal hyperplasia did not show any signs of progression during the 37-month follow-up. The rest of our patients discontinued all antiplatelet medication within 2-4 months despite our recommendation (clopidogrel for 3 months, ASA for life). They did not develop any symptoms or new angiographic findings.

This outcome supports the anecdotal observation by Chiaradio et $\mathrm{al},{ }^{35}$ who described a patient in whom antiplatelet therapy was stopped 4 weeks after stent graft placement for a vertebral artery aneurysm without the patient's developing symptoms. It also supports the prior experience by Madam et $\mathrm{al}^{20}$ who administered clopidogrel for 3 months and ASA for 6 months in 2 patients with CCF and stent grafts, who did not develop signs of thrombosis and demonstrated patency of the artery at 6 months angiographic follow-up. From prior animal studies, we know that PTFE-covered stents are well endothelized (over $90 \%$ of their surface area) in 4 weeks. ${ }^{36}$ Our observations add to prior reports in which minimal or no intimal hyperplasia was identified in patients treated with stent grafts for a vascular process other than atherosclerotic vaso-occlusive disease. ${ }^{20-22,24,25,30,32,37,38}$ This contrasts with the experience reported in the coronary and venous bypass circulation, where significant restenosis was reported in approximately $30 \%$ of the patients with known atherosclerotic disease and associated risk factors. ${ }^{39,40}$ Despite the encouraging preliminary results in our series and other similar series previously cited, the number of patients with CCF treated with covered stents remains small, and additional investigation is required to determine the long-term outcome of this treatment method. Although many of our patients stopped taking their antiplatelet medication prematurely, such an approach is not recommended.

The Jostent GraftMaster is a covered stent originally designed for coronary use with growing accumulated intracranial experience. Its main drawback for intracranial use is the limited longitudinal flexibility. To overcome this limitation, one must provide extra support to the stent by using a long sheath, a guide catheter, and a stiff exchange wire that contributes to straightening the vessel. ${ }^{21}$ Other groups have reported successful use of a self-expandable nitinol PTFE-covered stent, which, if more malleable and easier to navigate, might contribute to negotiating the tortuosity of the intracranial vasculature with enhanced safety. ${ }^{20,31,33}$

In addition to the stiffness of the delivery system, the Jostent itself can have limited flexibility, causing a straightened or more "vertical" course of the cavernous ICA after its deployment. In our experience and in this case series, this represented an anticipated finding with no associated symptoms or hemodynamic consequence.

These are encouraging results, and further progress can be anticipated as technology of the covered stents and their delivery systems continues to evolve. Stent-based artery reconstruction is a valid technique to treat CCF and could soon become a first-line therapy as experience with this device increases, materials continue to improve, and more data are accumulated.

\section{Conclusions}

With the technology, acquired knowledge, and experience available today, CCF can be treated and cured without sacri- 
ficing the parent vessel in nearly all patients. PTFE-covered stents are evolving as a promising intracranial therapeutic alternative to treat CCF and preserve the parent artery by reconstructing the arterial wall. It should be considered in patients in whom fistula cannot be successfully occluded with detachable balloons or detachable coils. The navigation of balloonexpandable covered stents in the intracranial circulation can be challenging. This limitation can be minimized by appropriately selecting the patients and by using a stable access system. More investigation is required to further develop the specifications and indications of patients to be selected.

\section{References}

1. Serbinenko FA. Balloon catheterization and occlusion of major cerebral vessels. J Neurosurg 1974;41:125-45

2. Debrun G, Lacour P, Caron JP, et al. Experimental approach to the treatment of carotid-cavernous fistulas with an inflatable and isolated balloon. Neuroradiology 1975;9:9-12

3. Debrun G, Lacour P, Caron JP, et al. Detachable balloon and calibrated-leak balloon techniques in the treatment of cerebral vascular lesions. J Neurosurg 1978;49:635-49

4. Debrun G, Lacour P, Vinuela F, et al. Treatment of $\mathbf{5 4}$ traumatic carotid-cavernous fistulas. J Neurosurg 1981;55:678-92

5. Lewis AI, Tomsick TA, Tew JM, et al. Long-term results in direct carotidcavernous fistula treatment with detachable balloons. J Neurosurg 1996;84:400-04

6. Norman D, Newton TH, Edwards M, et al. Carotid-cavernous fistula: closure with detachable silicone balloons. Radiology 1983;149:149-57

7. Luo CB, Teng MMH, Chang FC, et al. Transarterial balloon-assisted n-butyl2-cyanoacrylate embolization of direct carotid cavernous fistulas. AJNR Am J Neuroradiol 2006;27:1535-40

8. Debrun GM, Vinuela F, Fox AJ, et al. Indications for treatment and classification of 132 carotid-cavernous fistulas. Neurosurgery 1988;22:285-89

9. Goto K, Hieshima GB, Higashida RT, et al. Treatment of direct carotid-cavernous sinus fistulae: various therapeutic approaches and results in $\mathbf{1 4 8}$ cases. Acta Radiol Suppl 1986;369:576-79

10. Lewis AI, Tomsick TA, Tew JM. Management of 100 consecutive direct carotid-cavernous fistulas: results of treatment with detachable balloons. Neurosurgery 1995;36:239-45

11. Higashida RT, Halbach VV, Tsai FY, et al. Interventional neurovascular treatment of traumatic and vertebral lesion: results in 234 patients. AJR Am J Roentgenol 1989;153:577-82

12. Halbach VV, Higashida RT, Barnwell SL, et al. Transarterial platinum coil embolization of carotid-cavernous fistulas. AJNR Am J Neuroradiol 1991;12:429-33

13. Manelfe C, Berenstein A. Treatment of carotid cavernous fistulas by venous approach. J Neuroradiol 1980;7:13-19

14. Moron FE, Klucznik RP, Mawad ME, et al. Endovascular treatment of highflow carotid cavernous fistulas by stent-assisted coil placement. AJNR Am J Neuroradiol 2005;26:1399-404

15. Halbach VV, Higashida RT, Hieshima GB, et al. Transvenous embolization of direct carotid cavernous fistulas. AJNR Am J Neuroradiol 1988;9:741-47

16. Guglielmi G, Vinuela F, Duckwiler G, et al. High-flow, small-hole arteriovenous fistulas: treatment with electrode detachable coils. AJNR Am J Neuroradiol 1995;16:325-28

17. Bavinzski G, Killer M, Gruber A, et al. Treatment of post-traumatic caroticocavernous fistulae using electrolytically detachable coils: technical aspects and preliminary experience. Neuroradiology 1997;39:81-85

18. Suzuki S, Lee DW, Jahan R, et al. Transvenous treatment of spontaneous dural carotid-cavernous fistulas using a combination of detachable coils and Onyx. AJNR Am J Neuroradiol 2006;27:1346-49

19. Arat A, Cekirge S, Saatci I, et al. Transvenous injection of Onyx for casting of the cavernous sinus for the treatment of carotid-cavernous fistula. Neuroradiology 2004;46:1012-15. Epub 2004 Nov 9

20. Madan A, Mujic A, Daniels K, et al. Traumatic carotid-cavernous sinus fistula treated with a covered stent: report of two cases. J Neurosurg 2006;104:969-73

21. Felber S, Henkes $\mathrm{H}, \mathrm{Weber} \mathrm{W}$, et al. Treatment of extracranial and intracranial aneurysms and arteriovenous fistulae using stent grafts. Neurosurgery 2004;55:631-39

22. Kocer N, Kizilkilic O, Albayram S, et al. Treatment of iatrogenic internal carotid artery laceration and carotid cavernous fistula with endovascular stentgraft placement. AJNR Am J Neuroradiol 2002;23:442-46

23. Bouthillier A, van Loveren HR, Keller J. Segments of the internal carotid artery: a new classification. Neurosurgery 1996;38:425-33

24. Saatci I, Cekirge HS, Ozturk MH, et al. Treatment of internal carotid artery aneurysms with a covered stent: experience in 24 patients with mid term follow-up results. AJNR Am J Neuroradiol 2004;25:1742-49

25. Islak C, Kocer N, Albayram S, et al. Bare stent-graft technique: a new method of endoluminal vascular reconstruction for the treatment of giant and fusiform aneurysms. AJNR Am J Neuroradiol 2002;23:1589-95

26. Connors JJ III, Wojak JC. Interventional neuroradiology: strategies and practical techniques. Philadelphia: WB Saunders; 1999:215-26

27. Lee CY, Yim MB, Kim IM, et al. Traumatic aneurysm of the supraclinoid internal carotid artery and an associated carotid-cavernous fistula: vascular reconstruction performed using intravascular implantation of stents and coils. J Neurosurg 2004;100:115-19

28. Kim SH, Qureshi AI, Boulos AS, et al. Intracranial stent placement for the treatment of a carotid-cavernous fistula associated with intracranial angioplasty: case report. J Neurosurg 2003;98:1116-19

29. Wakhloo AK, Lanzino G, Lieber BB, et al. Stents for intracranial aneurysms: the beginning of a new endovascular era? Neurosurgery 1998;43:377-79

30. Redekop G, Marotta T, Weill A. Treatment of traumatic aneurysms and arteriovenous fistulas of the skull base by using endovascular stents. J Neurosurg 2001;95:412-19

31. Alexander MJ, Smith TP, Tucci DL. Treatment of an iatrogenic petrous carotid artery pseudoaneurysm with Symbiot covered stent: technical case reports. Neurosurgery 2002;50:658-62

32. Burbelko MA, Dzyak LA, Zorin NA, et al. Stent-graft placement for wide-neck aneurysm of the vertebrobasilar junction. AJNR Am J Neuroradiol 2004;25:608-10

33. Auyeung KM, Lui WM, Chow LC, et al. Massive epistaxis related to petrous carotid artery pseudoaneurysm after radiation therapy: emergency treatment with covered stent in two cases. AJNR Am J Neuroradiol 2003;24:1449-52

34. Blasco J, Macho JM, Burrel M, et al. Endovascular treatment of a giant intracranial aneurysm with a stent-graft. J Vasc Interv Radiol 2004;15:1145-49

35. Chiaradio JC, Guzman L, Padilla L, et al. Intravascular graft stent treatment of a ruptured fusiform dissecting aneurysm of the intracranial vertebral artery: technical case report. Neurosurgery 2002;50:213-17

36. Cheneau E, John MC, Fournadjiev J, et al. Time course of stent endothelialization after intravascular radiation therapy in rabbit iliac arteries. Circulation 2003;107:2153-58. Epub 2003 Apr 14

37. Rubartelli P, Terzi G, Borgo L, et al. Coronary artery aneurysm after stent implantation: acute and long-term results after percutaneous treatment with a stent-graft. Ital Heart J 2002;3:202-05

38. Briguori C, Sarais C, Sivieri G, et al. Polytetrafluoroethylene-covered stent and coronary artery aneurysms. Catheter Cardiovasc Interv 2002;55:326-30

39. Gercken U, Lansky AJ, Buellesfeld L, et al. Results of the Jostent coronary stent graft implantation in various clinical settings: procedural and follow-up results. Catheter Cardiovasc Interv 2002;56:353-60

40. Stankovic G, Colombo A, Presbitero P, et al. Randomized evaluation of polytetrafluoroethylene-covered stent in saphenous vein grafts. Circulation 2003; 108:37-42 